Bond University

Research Repository

\title{
Nutrition process improvements for adult inpatients with inborn errors of metabolism using the i-PARIHS framework
}

Williams, Clare; van der Meij, Barbara S.; Nisbet, Janelle; Mcgill, Jim; Wilkinson, Shelley A.

\section{Published in:}

Nutrition and Dietetics

DOI:

$10.1111 / 1747-0080.12517$

Licence:

Other

Link to output in Bond University research repository.

Recommended citation(APA):

Williams, C., van der Meij, B. S., Nisbet, J., Mcgill, J., \& Wilkinson, S. A. (2019). Nutrition process improvements for adult inpatients with inborn errors of metabolism using the i-PARIHS framework. Nutrition and Dietetics, 76(2), 141-149. https://doi.org/10.1111/1747-0080.12517

\section{General rights}

Copyright and moral rights for the publications made accessible in the public portal are retained by the authors and/or other copyright owners and it is a condition of accessing publications that users recognise and abide by the legal requirements associated with these rights.

For more information, or if you believe that this document breaches copyright, please contact the Bond University research repository coordinator 
Title: Nutrition process improvements for adult inpatients with inborn errors of metabolism using the i-PARIHS framework

Clare Williams ${ }^{1,3}$, Barbara S. van der Meij ${ }^{1,2,4}$, Janelle Nisbet ${ }^{3}$, Jim McGill ${ }^{3}$, Shelley A. Wilkinson ${ }^{1,4}$

Running title (<50 characters): Optimising nutrition in adults with IEM's

Authors details and affiliations:

Clare Williams, Senior Metabolic Dietitian, BHIthSc (Nutr\&Diet-Hons), APD

Barbara Suzanne van der Meij, Senior Research Conjoint Dietitian, PhD Janelle Nisbet, Endocrinologist and Metabolic Physician MBBS, FRACP, PhD Jim McGill, Senior Metabolic Consultant MBBS(Hons), FRACP, FRCPA, HGSA Shelley Ann Wilkinson, Senior Maternal Health Research Dieititan \& Queensland Department of Health Research Fellow, PhD, AdvAPD,

${ }^{1}$ Department of Dietetics and Food Services, Mater Health, South Brisbane, Queensland 4101, Australia

2 Faculty of Health Sciences and Medicine, Bond University, Robina, Queensland 4226, Australia

${ }^{3}$ Queensland Lifespan Metabolic Medicine Services, Mater Health, South Brisbane, Queensland 4101, Australia

${ }^{4}$ Mater Research Institute, University of Queensland, South Brisbane, Queensland 4101, Australia

\section{Authorship Declaration:}

All authors participated sufficiently in the article to take public responsibility for the content. Clare Kreis (corresponding author) facilitated the project, with supervision from Drs Barbara van der Meij and Shelley Wilkinson. Data collection, analysis and interpretation was completed by Clare Kreis. Clare Kreis was responsible for drafting the article with Drs Barbara van der Meij and Shelley Wilkinson providing significant critical input into the article and contributing to regular article reviews. Dr Janelle Nisbet and Dr Jim McGill were instrumental in the planning, development and evaluation of the innovations. They both also reviewed the article. All authors are in agreement with the manuscript and declare that the content has not been published elsewhere. Thanks to Anita Inwood and Sally McCray for their support and input into the project innovations. Thanks to Laura Hawke and Aman Marwah for assisting greatly with the development of menus suitable for patients with IEM.

Corresponding author:

Clare Williams, Metabolic Dietitian, Dietetics and Food Services, Level 3 Salmon Building, Mater Health, Raymond Terrace, South Brisbane, Queensland Australia 4101. Email: clare.williams@mater.org.au; Telephone: (07) 31636000 (prompts 2, then 3).

Conflict of Interest: The authors have no conflicts of interest to declare.

Funding: No funding was sourced for this project or manuscript. 


\begin{abstract}
Aim: This project aimed to implement consensus recommendations and innovations that improve dietetic services to promote timely referral to optimise nutritional management for adult inpatients with Inborn Errors of Metabolism (IEM). Methods: The i-PARIHS framework was used to identify service gaps, implement innovations and evaluate the innovations within this single-site study. The constructs of this framework are (i) review of the evidence, (ii) recognising patients and staff knowledge and attitudes (iii) acknowledging the local context, and (iv) the facilitators role. This included a literature review and metabolic centre service comparisons to investigate dietetic referral and foodservice processes to inform the innovation. A 12month chart audit ( 6 months retrospective and prospective of implemented innovation, respectively) to evaluate newly established dietetic referral and IEM nutrition provision procedures was also completed.

Results: The innovations implemented encompassed a clinical alert triggering urgent referral, nutrition sick day plans and metabolic diet and formula prescription via an 'alert' tab in electronic records. Eleven metabolic protein-restricted diets and nine formula recipes were introduced. Prior to the innovations, only 53\% $(n=19 / 36)$ of inpatients with Inborn Errors of Metabolism were assessed by the dietitian and received appropriate nutrition within 24 hours. Following implementation of the innovations, $100 \%(n=11 / 11)$ of inpatients with Inborn Errors of Metabolism received timely dietetic assessment and optimal nutrition.

Conclusion: Implementation of innovations developed using the i-PARIHS framework is effective in timely notification of the metabolic dietitian of referrals. This ensures optimal nutritional management during admissions which is required in this group of high-risk patients.
\end{abstract}

Key words:

Evidenced-based practice; Diet, Protein restricted; Diet therapy; Food services, hospital; i-PARIHS; Metabolism, inborn errors 
In today's healthcare arena there is mounting pressure to ensure that the delivery of service is evidence-based and clinically effective. ${ }^{1}$ Modern definitions of evidence-based practice (EBP) emphasise building upon clinical expertise by accessing research evidence and measuring its validity, applicability, and value to clients. ${ }^{2}$ This process is fundamental to ensure optimal patient outcomes. Despite awareness of how best to provide health services, failure to translate research into practice is common. ${ }^{3,4}$ This has driven the evolution of frameworks to provide a systematic and rigorous approach to the planning and evaluation of knowledge translation. The integrated-Promoting Action on Research Implementation in Health Services (i-PARIHS) is one such framework. ${ }^{5}$

In 2015, our Dietetics and Foodservices Department systematically addressed evidence-practice gaps in all dietetic caseloads. This process involved comparing clinical areas with relevant guidelines, high quality literature, and comparison services to identify evidence-practice gaps, before developing innovations to ensure best practice dietetic care.

This strategic and systematic process closely mapped the key constructs of the i-PARIHS framework. Fortuitously, this coincided with the establishment of a new adult metabolic service. Alongside this, was the departure of paediatric services from our hospital to form Children's Health Queensland (CHQ). Historically the paediatric services treated adult patients at our site, and adults across the state. This loss of expertise created a gap in care for adults with IEM and left our facility with minimal clinical experience, a lack of resources and unsupported referral and foodservice processors. The hospital acknowledged this service gap and recruited a trainee doctor, and established the state-wide Queensland Lifespan Metabolic Medicine Service (QLMMS) alongside CHQ. Over this time, an unexpected influx of adult IEM admissions occurred due the service expansion. No established referral or foodservice processes existed to accommodate adult metabolic admissions, resulting in a strain on the metabolic dietitian's caseload and highlighted the serious clinical risk associated with lack of appropriate food and formula provisions for IEM inpatients. The metabolic dietetic FTE increased from 0.5 to 0.7 to accommodate the absorption of all adult IEM patients across Queensland.

IEMs are a group of genetic disorders causing enzyme dysfunction affecting the normal metabolic pathways of proteins, carbohydrates, and fats. ${ }^{6}$ In the majority of the disorders problems arise due to accumulation of toxins derived from protein breakdown that interfere with normal function. ${ }^{7,8}$ Any given IEM is very rare, however the epidemiology of this group of disorders occur in 1 in 5000 live births. ${ }^{9,10}$ With the advancements of technology, diagnoses are occurring across all ages,. ${ }^{11,12,13}$ with up to $50 \%$ of IEMs presenting in later childhood and adulthood. ${ }^{9}$ Improved diagnosis and treatment options means more patients are surviving into adulthood with this trend expected to continue. ${ }^{6,14,15}$

Diet therapy is considered the cornerstone of many IEM treatments. ${ }^{13,} 15,17-19$ These patients can present with minor illness that can precipitate rapid decompensation and deterioration. ${ }^{9,13}$ Failure to provide immediate protein restricted, high energy metabolic formula and diet therapy aimed at minimising toxin accumulation and halting catabolism, can result in serious outcomes including mental retardation, neurologic crisis, and death. $7,9,10,13,14,16,17$

The current study describes our dietetic service improvement process for the metabolic caseload. Specifically, we present the identification of evidence-practice gap, and the development, implementation, and evaluation of an evidence-based 
model of care (the innovation) using the i-PARIHS framework to improve dietetic and nutrition provision services for adult inpatients with IEM.

Methods

This single-site metabolic dietetic service development process, which will be referred to as the innovation, was undertaken within the i-PARIHS framework for knowledge translation. ${ }^{5}$ The i-PARIHS framework involves four key constructs. ${ }^{5}$ First, sourcing and applying available evidence and data to inform the innovation; second, recognising recipients (patients and staff) as the people who are affected by and influence the innovation. The third construct accounts for local and wider organisational context that enables or constrains implementation. The fourth construct entails the facilitator activating implementation through assessing and responding to characteristics of the innovation within the contextual setting. Following this process enabled the facilitator to pinpoint barriers, assess influencing factors and negotiate implementation strategies with key stakeholders (including the patients) to translate research findings into clinical practice to improve nutrition for IEM inpatients.

Data to inform the innovation were drawn from a number of sources. These included a literature review; a service comparison; and audits of the metabolic dietetic service. Table 1 illustrates how the four i-PARIHS constructs informed the innovation. Further details on this are outlined below.

Literature review: Relevant guidelines, protocols, dietetic models of care and recommendations for metabolic foodservice and formula provision published from 2000 onwards were obtained from the Clinician Knowledge Network and a Cochrane review. The search was limited to IEM in the acute or emergency setting. Literature was only included if available in English and full text articles.

Service Comparison: Australian and New Zealand IEM centres were invited to respond to a questionnaire in November 2015 to collate current practices in dietetic service responsibilities and food/formula provisions across sites. A yes/no questionnaire, with descriptive components to allow comment was developed (Appendix 1). The questionnaire was emailed to ten metabolic specialist centres in Australia and New Zealand chosen by their professional association with the Australasian Society of Inborn Errors of Metabolism. The email invited the metabolic dietitian(s) and teams to respond from each centre. Participation was voluntary and consent was assumed with questionnaire return. Responses from the questionnaire were tallied.

Metabolic dietitian service audits: Chart audits at baseline (retrospective) and post innovation (prospective) were conducted to determine if IEM inpatients were assessed by a dietitian urgently (defined as within 24 hours of admission or next working day) and received optimal nutrition via prescription of specialised protein restricted, high energy diet and metabolic formula. Both audits captured data over six months. Hospital clinical coders extracted lists of IEM inpatients. Patients admitted for four hours or less, and those under 18 years were excluded. Data collected included documentation of dietetic assessment (yes/no); initial dietetic assessment conducted urgently (yes/no); and number of nutrition related clinical incidents. The data were de-identified and tabulated to allow comparisons over the two time points. The baseline audit reviewed the IEM inpatients admitted from $1^{\text {st }}$ February 2015 to $31^{\text {st }}$ July 2015. A search of nutrition-related clinical incidents for these inpatients logged over this same time period was also extracted. The same audit process took 
place following the implementation of the innovation. This prospective audit reviewed the IEM inpatients from $1^{\text {st }}$ November 2016 to $30^{\text {th }}$ April 2017. The time between audit periods was intended to allow for the innovation to be imbedded within the service. A timeline of events in represented in Figure 1. Descriptive statistical analysis was used to compare the results across the baseline and retrospective audits.

Utilising the constructs from the i-PARIHS framework, we sourced and collated available data from the literature review, service comparison and metabolic dietetic service audit. Action steps were negotiated and decided by the stakeholder team. Consideration for the staff and patients who would be affected by the innovation within our hospital context took place as a critical step in the i-PARIHS framework. This involved outpatient consultations with patients to establish dietary preferences and conducting nursing, foodservice and dietitian assistant training inservices. Strategies for overcoming barriers were discussed, with practical solutions identified and built into the action steps. The innovation for improving nutritional management and dietetic services for inpatients with IEM was developed from these findings.

This project received exemption from ethical approval from the hospital's Human Research Ethics Committee (HREC/17/MHS/42).

Results

Literature Review: Limited high quality evidence regarding treatment and dietary management of adults with IEMs was identified. Much of the literature and management plans obtained were based on paediatric populations and rated as class $C$ and $D$ evidence. ${ }^{20}$ The literature review did identify the effectiveness of clinical pathways and alerts referring inpatients to the metabolic team urgently with access to emergency management plans including immediate initiation of protein restricted diets in children, ${ }^{13-15,17,22-24}$ but failed to provide any advice for adults. It was recognised that advancements in diagnosis and treatment options results in IEM patients surviving into adulthood ${ }^{6}$ but there remains limited robust evidence due to lack of relevant clinical studies on management for this age group. ${ }^{18,21,23-27}$ The key findings from the literature are shown in the second column of Table 1.

Service Comparison: There was a $70 \%(n=7 / 10)$ response rate from the Australian and New Zealand IEM service comparison questionnaires. No consistency of process or pathways for referrals to dietitians, food and formula provision was reported across sites. All centres that responded reported that their services provide an urgent (within 24 hours of admission) referral to the metabolic team and dietitian. Over two-thirds $(71 \%, n=5 / 7)$ of the centres responded that clinical staff has full access to sick day nutrition plans. The remaining $28 \%(n=2 / 7)$ of centres provide on-call dietitians that activate these plans. The results of these service comparison questionnaires are in the third column in Table 1.

Metabolic Dietitian Service Audit: The results from the 6-month retrospective (baseline) audit revealed that only 53\% $(n=19)$ IEM patients from a total of 36 admissions were assessed by the metabolic dietitian within 24 hours or the next working day. This left $47 \%(n=17)$ inpatients not assessed in line with evidence recommendations. Of these, $14 \%(n=5)$ of patients did not receive dietetic assessment urgently, leaving a third $(33 \% \mathrm{n}=12)$ of IEM inpatients discharged without dietetic assessment at all. From all 36 IEM admissions, only $8 \%(n=3)$ had a nutrition-related clinical incident logged regarding inaccurate foodservice provisions. 
The retrospective chart audit identified another $14 \%(n=5)$ of patients had been allocated inaccurate diet codes. Nutrition-related clinical incidents should have been logged for these errors but as a third of patients had no dietetic input, and clinical staff did not realise the errors, these incidents were missed. Retrospectively this accounts for $22 \%(8 / 36)$ of pre-innovation incident errors.

Results from the prospective (post innovation) audit show that $100 \%(n=11)$ of patients admitted were assessed by the metabolic dietitian within 24 hours of admission or the next working day achieving evidence recommendations. Of the 11 IEM admissions over this prospective audit, $9 \%(n=1)$ had a nutrition-related clinical incident logged for inaccurate foodservice provision. All other patients were provided a protein-restricted diet and metabolic formula prescribed on their sick day plan. These results are shown in Figure 2.

Change in Practice: As a result of using the i-PARIHS framework, combining the findings from the literature review, service comparison, and metabolic dietitian service audit, three action steps that form the metabolic dietetic service innovation were developed. These were:

- Creation of an electronic referral alert,

- Access to metabolic sick day nutrition plans for all clinical staff, and

- Establishment of metabolic diet codes and specialised formula recipes.

Referral alert: All IEM patients known to the metabolic service were assigned an alert on their electronic medical record. This alert prompts an urgent referral to the metabolic team, including the metabolic dietitian. The clinicians are available 24/7 and can action the sick day nutrition plans with prescribed protein restricted diets and formulas in the absence of on-call dietetics.

Access to metabolic sick day nutrition plans: Since the innovation, IEM inpatients who require an individualised sick day nutrition plan have these in place via the 'alerts' tab in the electronic medical record. The sick day nutrition plans include comprehensive instruction for individualised protein restricted, high-energy diet prescription, with recipes for specialised formula to promote metabolic stability. Clinical staff access these sick day nutrition plans, allowing prompt actioning of diet codes via the hospital foodservice interface. Data for frequency of use of these sick day nutrition plans cannot be compiled, but during the implementation, all patient plans were applied to the alert tab.

Establishment of metabolic diet codes and specialised formula: In response to the inadequate provision of foodservices for IEM inpatients, a review of the menu occurred. During this time, the hospital was transitioning to Room Service Choice on Demand food delivery system. ${ }^{28}$ Eleven new specialised protein restricted metabolic diet codes were developed. These included specialised medical foods reserved for patients with IEMs to improve food variety. Additionally nine metabolic formula recipes were created. The pre- and post-implementation data is described in Tables 2 and 3 respectively. These diet codes and formula recipes were added to the hospital foodservice interface allowing clinical staff to allocate the dietary prescription as recommended in the sick day nutrition plans.

\section{Discussion}

This service development strategy used the i-PARIHS framework to develop, implement, and evaluate an innovation to improve nutrition services for adult inpatients with IEM. Through a consensus process of data gathering and stakeholder discussion, the lack of evidence in the literature was overcome to develop this 
dietetic service improvement. Despite the lack of robust evidence, we showed that electronic referral alerts, clinical staff access to sick day nutrition plans and incorporation of protein restricted metabolic diet codes and formula recipes are successful in improving nutrition management and timeliness of dietetic services for adult IEM inpatients to reflect evidence recommendations.

As the hospital metabolic service developed over the 2015-2017 project period, a reduction in total IEM admissions occurred (i.e. 36 vs 11 across the different audit periods). This clear reduction may be accounted for by the improvement in outpatient metabolic services. More thorough education of the sick day nutrition plans and dietary management in the outpatient clinic setting occurred. This meant patients were able to activate their sick day therapy immediately at home, contributing to fewer hospital admissions. During the post-implementation audit period, two patients were excluded from the data collection as their admission was less than four hours. Interestingly, for both presentations, the electronic sick day nutrition plan was initiated by clinical staff and an urgent referral made to the metabolic dietitian, further supporting the success of the overall innovation.

To our knowledge this is the first paper that specifically addresses dietetic service and nutrition improvements for adult inpatients with IEMs despite many recognising its importance. Unlike other common dietetic caseloads such as oncology and malnutrition where more robust clinical guidelines exist, IEM is an expanding field of dietetic practice, especially within adult services. Demirdas and colleagues have highlighted that in the absence of robust evidence, multidisciplinary cooperation using clinical pathways will improve communication and provide clear direction for best care, ${ }^{23}$ but did not specifically detail the dietitians role or nutrition component of the clinical pathway. Additionally Camp and colleagues recognised the gaps in knowledge regarding the safety and utility of nutritional interventions for the management of IEMs. They also noted that these gaps can only be filled with further evidence-based research ${ }^{18}$ such as that undertaken in this paper.

Due to lack of evidence specific for provision of dietetic services, the innovation was generated using combined findings from the literature, service comparison, and dietetic service audits. The intuitive appeal and relevance to real world settings of the i-PARIHS framework ${ }^{5}$ means that the facilitator could adapt the innovation to encompass the local and organisational context, such as having no oncall dietitians and building diet codes and formula recipes into the room service system before implementation.

Several studies recognise that the management of these disorders can be complicated and should always involve a metabolic team including an experienced metabolic dietitian. ${ }^{9}, 13-15,19,29$ Indeed, Acosta and Singh highlight the significance of metabolic dietitians' role in ascertaining nutrient requirements, calculating compositions of formula, and provision of specialised prescriptive diets. ${ }^{14,19}$ It is recognised that metabolic emergencies are one area of healthcare where therapeutic strategies fall short from an evidence-base due to the lack of high quality research, in particular, a lack of evidence in the management of adults in acute hospital settings. ${ }^{18,23,30}$

Strengths of this project include the facilitator's relationship with stakeholders and their keen support of the innovation. Without a facilitator linked closely with the service who is aware of the patient group, limitations and importance of the metabolic diet therapy, and local constraints of the hospital context, the innovations could have failed. The facilitator is the active element, assessing, aligning, and integrating the other three constructs of the i-PARIHS framework. ${ }^{5}$ The role of the 
facilitator to drive the innovation into action is a key element of the framework and proved successful in this instance.

A limitation of this study is that it only measured two variables (dietitian assessment and nutrition provisions). Time constraints and stakeholder negotiations to focus on priority needs meant that other efficacies of treatment such as reduced length of stay, accuracy of nutritional provisions vs RDI, patient satisfaction and reduction in dietitian man-hours were not assessed. The significance of these variables lends scope for expansion of this study in the future.

The results from the service comparison across IEM centres in Australia and New Zealand showed similar innovations are evolving. Five of the seven centres were also establishing new metabolic services or reviewing their local sick day nutrition processes and foodservice provision to improve IEM inpatient care. The findings of this investigation align with the literature explored, showing that expert opinion and consensus may be the only supporting evidence when improving inpatient dietary provision for IEM patients.

Outcomes from this project will inform our metabolic dietetic service to continue to monitor and improve adult IEM inpatients nutritional management. Despite our local successes, it is clear that more research is needed to investigate how best to optimise nutritional provision and dietetic services for adult with these rare genetic conditions. Future projects include collaboration between IEM centres to develop Australasian guidelines for nutrition provision, and identification of micronutrient deficiency risk in IEM groups based on formula intake and compliance.

\section{Conclusion}

Use of the i-PARIHS framework was successful in developing an innovation that was effective in resulting in improving nutritional services for adult inpatient with IEM within this single site. Despite this, the ongoing need for evidence-based research to investigate specific responsibilities of the metabolic dietitian and define nutrition care pathways for these inpatients is warranted. Health innovations developed using i-PARIHS will improve patient care for this group of complex patients; particularly at our site, as the adult IEM population continues to expand. 


\section{References}

1. Rycroft-Malone J. The PARIHS framework-a framework for guiding the implementation of evidence-based practice. JNCQ 2004; 19(4): 297-304.

2. Straus SE, Richardson WS, Glasziou P, Haynes R. Evidence-based medicine: how to practice and teach EBM. Edinburgh: Elsevier Churchill Livingston, 2005.

3. Byham-Gray LD, Gilbride JA, Dixon LB, Stage FK. Evidence-based practice: what are dietitians' perceptions, attitudes, and knowledge? JADA.

2005;105(10):1574-81. Epub 2005/09/27.

4. Vogt E, Byham-Gray L, Touger-Decker R. Perceptions, attitudes, knowledge, and clinical use of evidence-based practice among US registered dietitians. Top Clin Nutr 2015; 28(3): 283-94.

5. Harvey G, Kitson A. PARIHS revisited: from heuristic to integrated framework for the successful implementation of knowledge into practice. Implement Sci 2016; 11: 33-44.

6. Bay C, Reid C, Daub A. Adolescents and adults with inborn errors of metabolism. Int J Disabil Hum Dev 2010; 9(2): 167-75.

7. El-Hattab AW. Inborn errors of metabolism. Clin Perinatol 2015; 42(2): 413-

39.

8. Schneller JL, Lee CM, Bao G, Venditti CP. Genome editing for inborn errors of metabolism: advancing towards the clinic. BMC Med 2017; 15(1): 43.

9. Fletcher JM. Metabolic emergencies and the emergency physician. JPCH 2016; 52(2): 227-30.

10. Jeanmonod R, Jeanmonod D. Inborn Errors Of Metabolism. StatPearls Publishing: National Centre for Biotechnology Information; 2017. (Available from: http://www.ncbi.nlm.nih.gov/pubmed/29083820, accessed 24 August 2018).

11. Kamboj M. Clinical approach to the diagnoses of inborn errors of metabolism. Pediatr Clin N Am 2008; 55(5): 1113-27.

12. Christodoulou J. Clinical evaluation and emergency management of inborn errors of metabolism presenting in the newborn. SE Asian J Trop Med 2003; 34 Suppl 3:189-97.

13. Gupta N, Kabra M. Acute management of sick infants with suspected inborn errors of metabolism. Indian J Pediatr 2011; 78(7): 854-9.

14. Acosta $P$, Ryan $A$. Functions of dietitians providing nutrition support to patients with inherited metabolic disorders. JADA 1997; 97(7): 783-6.

15. Burton H, Sanderson S, Dixon M, Hallam P, White F. Review of specialist dietitian services in patients with inherited metabolic disease in the United Kingdom. J Hu Nutr Diet 2007; 20(2): 84-92.

16. Saudubray JM, Sedel F, Walter JH. Clinical approach to treatable inborn metabolic diseases: an introduction. J Inherit Metab Dis 2006; 29(2-3): 261-74.

17. Vernon HJ. Inborn Errors of Metabolism: Advances in Diagnosis and Therapy. JAMA Pediatr 2015; 169(8): 778-82.

18. Camp KM, Lloyd-Puryear MA, Yao L, et al. Expanding research to provide an evidence base for nutritional interventions for the management of inborn errors of metabolism. Mol Genet Metab 2013; 109(4): 319-28.

19. Singh $\mathrm{RH}$, Kaczmarczyk MM. Standards of professional practice for genetic metabolic dietitians. Genet Med 2008; 10(4): 290-3.

20. National Health and Medical Research Council. How to review the evidence: systematic identification and review of the scientific literature. Canberra:

Commonwealth of Australia; 1999. 
21. McCain M, McGrath R, Stransky M, Benkendorf J. National survey of providers treating patients with metabolic disorders identified by newborn screening demonstrate challenges faced by clinical care systems. Clin Pediatr 2015; 54(8): 759-64.

22. Zand DJ, Brown KM, Lichter-Konecki U, Campbell JK, Salehi V, Chamberlain JM. Effectiveness of a clinical pathway for the emergency treatment of patients with inborn errors of metabolism. Pediatrics 2008; 122(6): 1191-5.

23. Demirdas S, van Kessel IN, Korndewal MJ, et al. Clinical pathways for inborn errors of metabolism: warranted and feasible. Orphanet J Rare Dis 2013; 8: 37.

24. British Inherited Metabolic Disease Group. Emergency Guidelines for Adults; 2018. (Avaialble from: http://www.bimdg.org.uk/guidelines/guidelines-adult.asp, accessed 25 August 2018).

25. Rice GM, Steiner RD. Inborn Errors of Metabolism (Metabolic Disorders). Pediatr Rev 2016; 37(1): 3-15.

26. Steiner RD. Evidence based medicine in inborn errors of metabolism: is there any and how to find it? Am J Med Genet A 2005; 134A(2): 192-7.

27. Wilcken B. Clinical practice and the development of evidence. J Inherit Metab Dis 2012; 35(1): 3-4.

28. McCray S, Maunder K, Krikowa R, MacKenzie-Shalders K. Room Service Improves Nutritional Intake and Increases Patient Satisfaction While Decreasing Food Waste and Cost. J Acad Nutr Diet 2018; 118(2): 284-93.

29. Dixon M. Disorders of amino acid metabolism: Organic acidemias and urea cycle defects. In: Shaw V, editor. Clinical Pediatric Dietetics, 4th ed. Hoboken, USA: Wiley Blackwell; 2007; 357-89.

30. Ewing $P$, Wiebe R. Evidence-based management of metabolic emergencies in the pediatric emergency department. Pediatr Emerg Med Pract 2009; 6(10): 1-12. 


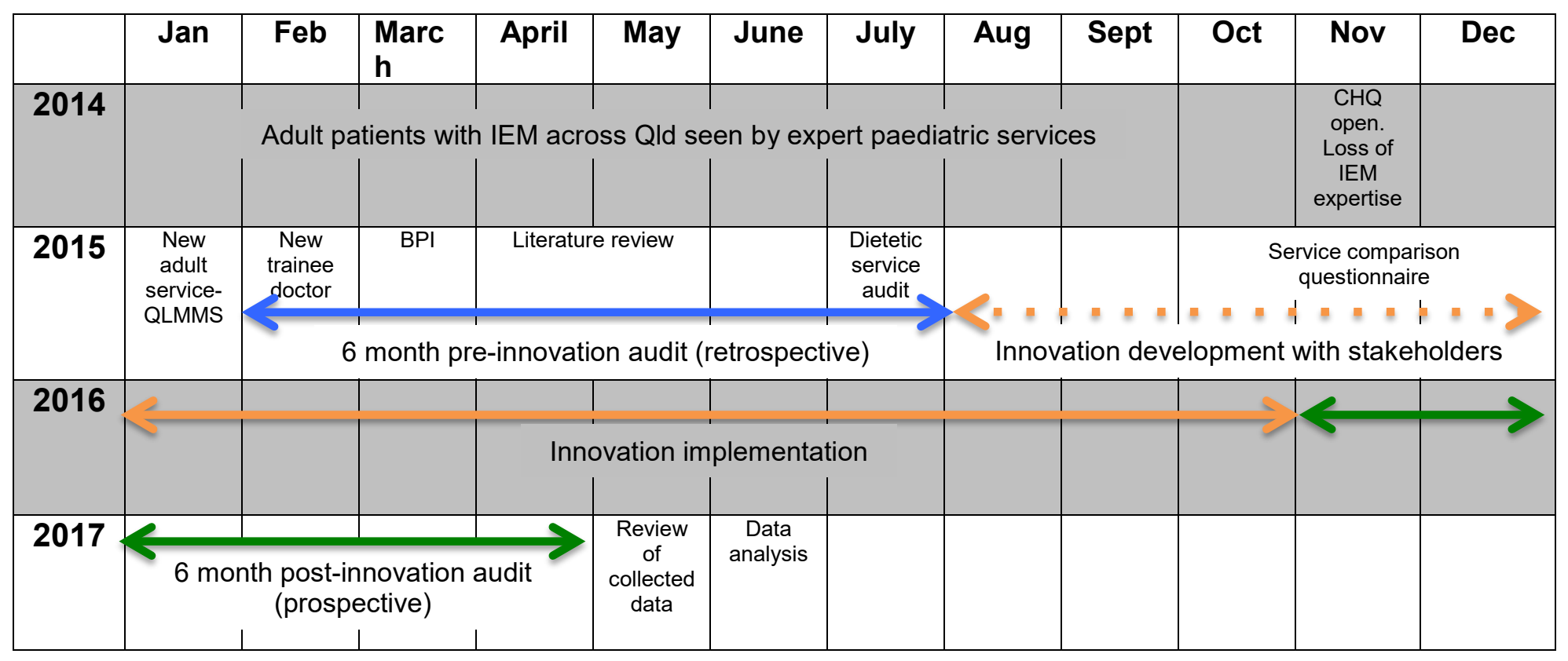

Figure 1: Timeline of events for process improvement innovation of nutrition services for inpatients with IEM 


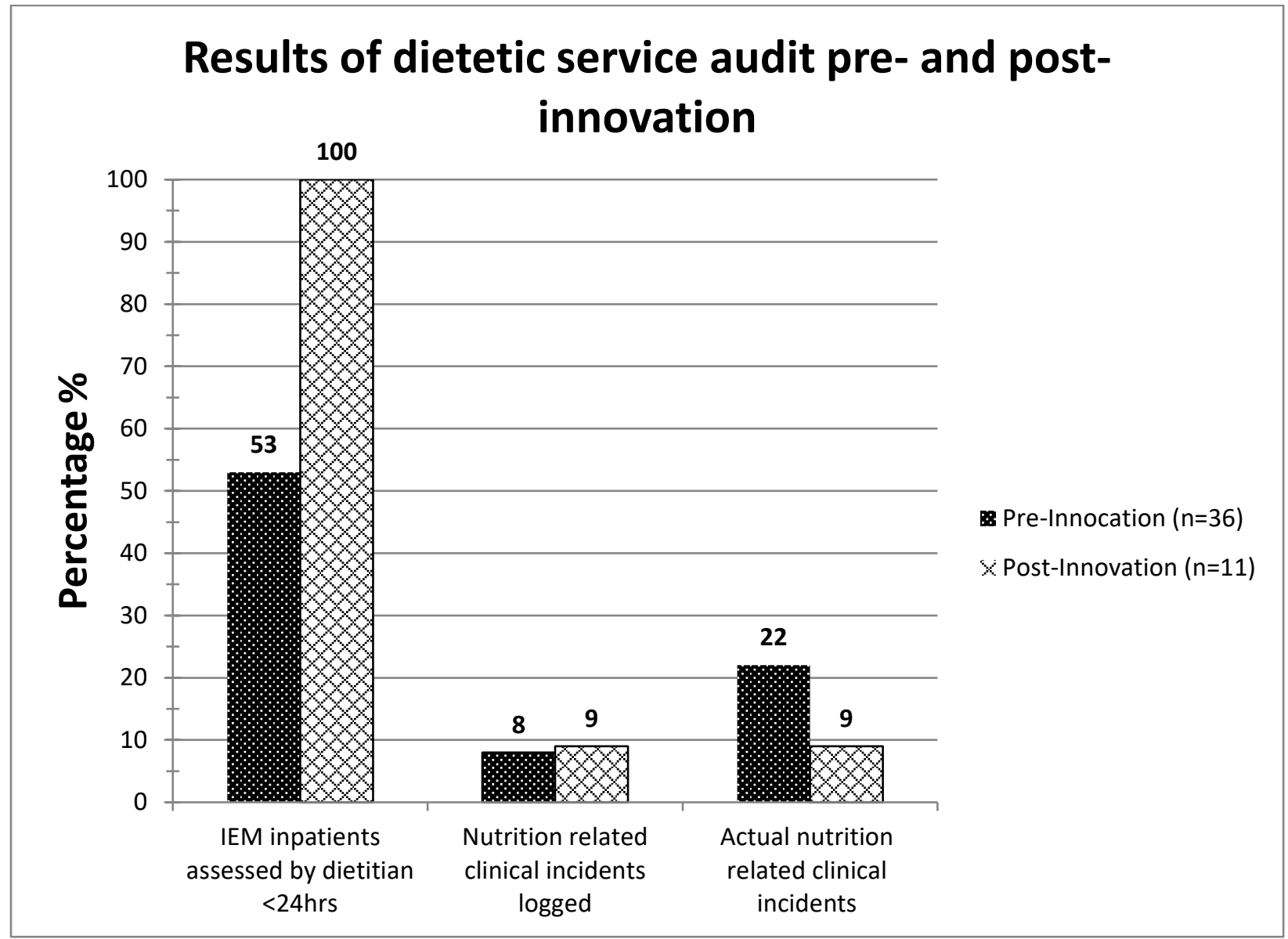

Figure 2: Results from the dietetic service audit for percentage of IEM inpatients assessed $<24 \mathrm{hrs}$ of admission (or next working day) and nutrition related clinical incidents pre- and post-innovation. 


\begin{tabular}{|c|c|c|c|}
\hline $\begin{array}{l}\text { The } 4 \text { i-PARIHS } \\
\text { key constructs }\end{array}$ & $\begin{array}{l}\text { Literature findings on research in } \\
\text { practice }\end{array}$ & $\begin{array}{l}\text { State of current practice } \\
\text { Aus \& NZ (n=7) }\end{array}$ & Change in Practice \\
\hline \multirow[t]{6}{*}{$\begin{array}{l}\text { 1. Souring and } \\
\text { applying available } \\
\text { evidence to inform } \\
\text { innovation }\end{array}$} & \multirow[t]{3}{*}{$\begin{array}{l}\text { All patients are to be referred to the } \\
\text { metabolic team urgently (within } 24 \mathrm{hrs} \text { ) } \\
\text { of admission, including assessment by } \\
\text { an experienced metabolic dietitian }\end{array}$} & $\begin{array}{l}\text { 71\% of centres have an alert or } \\
\text { trigger that prompts a direct } \\
\text { metabolic referral for IEM } \\
\text { admissions }\end{array}$ & $\begin{array}{l}\text { Clinical alert added to electronic } \\
\text { medical record for all IEM } \\
\text { patients }\end{array}$ \\
\hline & & $\begin{array}{l}\mathbf{1 0 0 \%} \text { of centres provide a } \\
\text { blanket dietitian referral for } \\
\text { IEM assessment }\end{array}$ & $\begin{array}{l}\text { Clinical alert prompts urgent } \\
\text { referral to dietitian }\end{array}$ \\
\hline & & $\begin{array}{l}100 \% \text { of centres provide initial } \\
\text { dietetic assessment for IEM } \\
\text { inpatients within a } 24 \mathrm{hr} \\
\text { timeframe }\end{array}$ & $\begin{array}{l}\text { Dietitian able to assess IEM } \\
\text { patients within } 24 \mathrm{hrs} \text { of } \\
\text { admission }\end{array}$ \\
\hline & \multirow[t]{3}{*}{$\begin{array}{l}\text { Clinical staff/s need to have immediate } \\
\text { access to individualised IEM sick day } \\
\text { diet and medical management plans }\end{array}$} & $\begin{array}{l}71 \% \text { of centres allow all clinical } \\
\text { staff access to specialised IEM } \\
\text { sick day nutrition plans }\end{array}$ & $\begin{array}{l}\text { Metabolic sick day nutrition plans } \\
\text { made available to all clinical staff }\end{array}$ \\
\hline & & $\begin{array}{l}86 \% \text { of centres supply standard } \\
\text { no protein, high-energy } \\
\text { metabolic formula prepared in } \\
\text { a sterile environment }\end{array}$ & $\begin{array}{l}\text { Hospital formula room prepare } \\
\text { metabolic formula from one of } 9 \\
\text { standard recipes }\end{array}$ \\
\hline & & $\begin{array}{l}71 \% \text { of hospital kitchens } \\
\text { provide specialised metabolic } \\
\text { foods and protein-restricted } \\
\text { diets for IEM inpatients }\end{array}$ & $\begin{array}{l}3 \text { new food items and } 11 \\
\text { specialised low protein diet } \\
\text { codes added to room service }\end{array}$ \\
\hline \multirow{3}{*}{$\begin{array}{l}\text { 2. Recipients as } \\
\text { people who are } \\
\text { affected by and } \\
\text { influence the } \\
\text { innovation }\end{array}$} & $\begin{array}{l}\text { Require a specialised protein restricted, } \\
\text { high-energy diet and metabolic formula } \\
\text { to meet the individualised nutritional } \\
\text { needs }\end{array}$ & \multirow{3}{*}{$\mathrm{N} / \mathrm{A}$} & $\begin{array}{l}11 \text { new protein restricted, high- } \\
\text { energy diet codes and } 9 \text { formula } \\
\text { recipes added to room service }\end{array}$ \\
\hline & $\begin{array}{l}\text { IEM patients were educated about the } \\
\text { innovation in clinic and individuals } \\
\text { consulted about food and formula } \\
\text { preferences }\end{array}$ & & $\begin{array}{l}\text { Individualised sick day plans are } \\
\text { reviewed } 2^{\text {nd }} \text { yearly and } \\
\text { negotiated with the IEM patient }\end{array}$ \\
\hline & $\begin{array}{l}\text { Stakeholder negotiations and } \\
\text { transparency of communication with } \\
\text { innovation progress }\end{array}$ & & $\begin{array}{l}\text { Ongoing in servicing, formula } \\
\text { room training for staff. q6/12 } \\
\text { audits continue }\end{array}$ \\
\hline \multirow{2}{*}{$\begin{array}{l}\text { 3. Accounting for } \\
\text { local and wider } \\
\text { organisational } \\
\text { context that can } \\
\text { enable or constrain } \\
\text { implementation }\end{array}$} & $\begin{array}{l}\text { Our site providing care for all IEM adult } \\
\text { patients as part of Queensland Lifespan } \\
\text { Metabolic Medicine Service }\end{array}$ & \multirow[b]{2}{*}{ N/A } & $\begin{array}{l}\text { Dietitian FTE increase from } \\
0.5 \rightarrow 0.7 \text { to accommodate influx }\end{array}$ \\
\hline & $\begin{array}{l}\text { No on-call dietetic services available at } \\
\text { this hospital }\end{array}$ & & $\begin{array}{l}\text { Clinical staff can activate } \\
\text { metabolic diet codes and formula } \\
24 / 7 \text { with instructions provided } \\
\text { on sick day plans }\end{array}$ \\
\hline \multirow{2}{*}{$\begin{array}{l}\text { 4. The facilitator } \\
\text { activating } \\
\text { implementation } \\
\text { though assessing } \\
\text { and responding to } \\
\text { characteristics of } \\
\text { the innovation } \\
\text { within the } \\
\text { contextual setting }\end{array}$} & $\begin{array}{l}\text { Robust relationship between facilitator } \\
\text { dietitian and metabolic team, dietetics } \\
\text { department, food services and formula } \\
\text { room }\end{array}$ & \multirow[b]{2}{*}{ N/A } & $\begin{array}{l}\text { Metabolic dietitian good } \\
\text { interpersonal skills and } \\
\text { leadership to drive the project }\end{array}$ \\
\hline & $\begin{array}{l}\text { Dietitian facilitator familiar with the IEM } \\
\text { patients, the significance of the } \\
\text { innovation to their overall health } \\
\text { outcomes and the ward staff }\end{array}$ & & $\begin{array}{l}\text { Metabolic dietitian active in IEM } \\
\text { caseload and ongoing rapport } \\
\text { development with patients via } \\
\text { continued nutrition therapy and } \\
\text { care }\end{array}$ \\
\hline
\end{tabular}

Table 1: State of current practice for IEM as per i-PARIHS framework that formed the innovation for metabolic dietitian process improvements. 


\begin{tabular}{|c|c|c|c|c|}
\hline & $\begin{array}{l}\text { Reserved foods for } \\
\text { IEM diet codes }\end{array}$ & Diet Code & $\begin{array}{l}\text { Protein Range } \\
\text { (grams) }\end{array}$ & $\begin{array}{c}\text { Energy Range } \\
(\mathrm{kJ} / \mathrm{kg} / \mathrm{d})\end{array}$ \\
\hline $\begin{array}{c}\text { Pre- } \\
\text { innovation }\end{array}$ & Nil standard items & Low protein $35 \mathrm{~g}$ & $\leq 35 \mathrm{~g}$ & Not specified \\
\hline \multirow{11}{*}{$\begin{array}{c}\text { Post- } \\
\text { innovation }\end{array}$} & \multirow{5}{*}{ Prozero milk } & Low protein 0g (Metabolic) & 0 & $125-145$ \\
\hline & & Low protein $2 \mathrm{~g}$ (Metabolic) & 2 & $125-145$ \\
\hline & & Low protein 4g (Metabolic) & 4 & $125-145$ \\
\hline & & Low protein $8 \mathrm{~g}$ (Metabolic) & 8 & $125-145$ \\
\hline & & Low protein 10g (Metabolic) & 10 & $125-145$ \\
\hline & \multirow{6}{*}{$\begin{array}{l}\text { Protein free herb } \\
\text { crackers }\end{array}$} & Low protein 12g (Metabolic) & 12 & $125-145$ \\
\hline & & Low protein 15g (Metabolic) & $14-16$ & $125-145$ \\
\hline & & Low protein $20 \mathrm{~g}$ (Metabolic) & $18-21$ & $100-125$ \\
\hline & & Low protein 25g (Metabolic) & $23-26$ & $100-125$ \\
\hline & & Low protein 30g (Metabolic) & $28-32$ & $100-125$ \\
\hline & & Low protein $35 \mathrm{~g}$ (Metabolic) & $33-37$ & $100-125$ \\
\hline
\end{tabular}

Table 2: A nutritional description of the specialised protein-restricted IEM diet codes and reserved food items available following the innovation. 